\section{Durable polymer versus bio- absorbable polymer drug- eluting stents in right coronary artery chronic total occlusions: Eighteen months (median) results of a single-center experience}

Objective: There are a few data regarding the long-term clinical outcomes of durable polymer (DP) drug-eluting stents (DES) versus bio absorbable polymer (BP) drug-eluting stents treatment in patients with right coronary artery (RCA) chronic total occlusion (CTO). The aim of this study was to compare the clinical outcomes of these stents according to their polymer-based difference.

Methods: Between June 2013 and August 2016, 66 RCA CTO patients enrolled in the study. Fortyseven patients with successful CTO recanalization of RCA via ante grade or retrograde approach using either DP $(n=25)$ and BP $(n=22)$ were scheduled for 6,12 , and 18 months clinical follow-up. Primary clinical outcomes were cardiac death and major adverse cardiac events (MACE).

Results: RCA CTO success rate was $71 \%$. There was no difference in Japanese-CTO (JCTO) scores between two groups. Total stent length was longer in BP group, and it was statistically significant $(p=0.015)$. The incidence of cardiac death was not significant between the two groups. After propensity score matching, TVR rates were $12.0 \%$ for DP group and $9.1 \%$ for BP group at the end of the 18 th month (hazard ratio $[H R]=0.815 ; 95 \%$ confidence interval $[\mathrm{Cl}]=0.123-5.418 ; \mathrm{p}=0.832$ ) and composite MACE rates were $16.0 \%$ for DP group and $15.0 \%$ for BP group (hazard ratio $[\mathrm{HR}]=0.926$; $95 \%$ confidence interval $[\mathrm{Cl}]=0.182-4.718 ; \mathrm{p}=0.927)$.

Conclusion: This study shows that the efficacy of BP-DES is comparable to that second-generation DP-DES treatment for RCA CTO over 18-month follow-up.

Keywords: Bio-absorbable polymer - Durable polymer - Chronic total occlusion - Drug-eluting stent $\cdot$ Right coronary artery

\section{Introduction}

Nearly $15-23 \%$ of patients who undergo coronary angiography (CCA) are CTOs, with success rates of only 55-90\% [1-5]. DES has been shown to improve the outcome of coronary artery disease patients with DM or CTOs [6-9]. The risk for restenosis and repeat revascularization is higher due to lesion complexity in CTO lesions. But the outcomes may result in differences with modern DES. There are limited data regarding the longterm clinical outcomes of DP versus BP stents in RCA CTOs who undergo PCI.

We examined the clinical outcome of DP versus BP stents after recanalization of
Davran Cicek*

Baskent University Alanya Medical Center, Antalya, Alanya, Turkey *Author for correspondence: Tel: +905323336466 $+902425102525$

E-mail: davrancicek@mynet.com Submitted: October 09, 2017 Accepted: October 27, 2017 Published online: October 31, 2017 
right coronary CTOs by the antegrade or retrograde approach.

\section{Methods}

Chronic total occlusion is defined as an obstruction of a native coronary artery for at least 3 months [1012]. The duration of CTO was estimated according to the last acute coronary syndrome (ACS) episode and previous coronary angiogram and first angina episode for patients without ACS history [13-15]. The inclusion criteria for the trial were (a) RCA CTO on a diagnostic coronary angiography and (b) a positive functional ischemia study and/or symptomatic angina. Exclusion criteria are (a) history of cardiopulmonary resuscitation or cardiogenic shock and (b) acute coronary syndromes. Between June 2013 and August 2016, 47 patients with successful CTO recanalization of RCA via antegrade or retrograde approach using either DP $(\mathrm{n}=25)$ or BP $(\mathrm{n}=22)$ DES were included in a single-center observational study. We used Nobori (Terumo Corporation, Tokyo, Japan) biolimus-eluting stents (BES) and Biomatrix (Biosensors International, Singapore) as the BP-based DES and C10/C19/PVP polymer-based slow-release ZES (Resolute, Medtronic) and phosphorylcholine polymer-based fast-release zotarolimus-eluting stents (PC-ZES) (Endeavor, Medtronic, Minneapolis, Minnesota) as DP-based DES. During the study period, successful CTO recanalization was performed in 47 out of 66 patients. Patients gave written informed consent. The study was approved by the local ethics committee. Patients were scheduled for 6, 12 and 18 months clinical follow-up.

Primary clinical outcomes were cardiac death and major adverse cardiac events (MACE), defined as a composite of myocardial infarction clearly attributable to the target vessel, target lesion failure (TLF), and cardiac death. TLF was a combined endpoint including target lesion revascularization (TLR), cardiac death, target-vessel myocardial infarction, stent thrombosis, or occlusion of the target lesion. Definite or probable stent thrombosis was defined according to the ARC (Academic Research Consortium) criteria [16].

All deaths were considered to be of cardiac origin unless a definite non-cardiac cause could be established. MI was defined as an elevation of the creatine kinaseMB fraction or the troponin- $\mathrm{T} /$ troponin-I level greater than the upper normal limit with concomitant ischemic symptoms or electrocardiographic findings indicative of ischemia [17]. All coronary interventions were performed by standard technique; and treatments were performed according to new guidelines. All patients, regardless of stent type, received a $300 \mathrm{mg}$ loading dose of aspirin and a $600 \mathrm{mg}$ loading dose of clopidogrel before the intervention. After PCI dual antiplatelet therapy with clopidogrel $75 \mathrm{mg}$ per day, acetylsalicylic acid $100 \mathrm{mg}$ per day was prescribed for 12 months. DES was used without restriction.

Statistical analysis: Continuous variables are expressed as mean (SD) or median (IQR). Categorical variables are expressed as percentages (\%) and numerics. Distribution of continuous variables was tested by Kolmogorov-Smirnov test. Continuous variables for two independent groups were compared by Student's $\mathrm{t}$ test or Mann-Whitney U test depending on distribution pattern. Categorical variables for two independent groups were compared by Fisher's exact test. Cumulative incidence of adverse events was calculated according to the Kaplan-Meier method, and differences were assessed using the log-rank test. All statistical tests were two-tailed, and $\mathrm{p}<0.05$ was considered statistically significant.

\section{Results}

We retrospectively evaluated the clinical outcomes of 47 patients who underwent CTO PCI of RCA in our institution. We enrolled the patients who were treated by drug-eluting stents with DP (25 patients) or with BP (22 patients). Descriptive clinical characteristics were similar in both groups except more intense statin and betablocker usage were existing in the BP group. Patients with diabetes mellitus were $48.0 \%$ in DP group and $40.9 \%$ in BP group (Table 1).There was no difference in J-CTO scores between durable and BP groups. Mean J-CTO score was $2.9(0.4)$ in DP group and was 3.0 (0.4) in BP group $(\mathrm{p}=0.537)$ (Table 2). Maximum and minimum stent diameters were similar in both groups. Total stent lengths per patient did not distribute normally, so they were expressed in median and IQR. Total stent length was longer in the BP group, and it was strongly significant statistically. Median stent length was $30.0 \mathrm{~mm}(24.0-61.0 \mathrm{~mm})$ in the DP group and $56.0 \mathrm{~mm}(33.0-65.0 \mathrm{~mm})$ in the BP group $(\mathrm{p}=0.015)$. Nearly all of the patients were treated by antegrade approach; there was only one retrograde approach in the $\mathrm{BP}$ group. Two patients from the BP group died during in-hospital follow-up. In-hospital mortality was not statistically significant between two groups $(\mathrm{p}=0.214)$ (Table 3). There was not any emergent CABG or surgical intervention need during in-hospital follow-up. We did not detect any tamponade case, and we reported only one coronary perforation, which was treated successfully by long-standing balloon inflation. There was only one 


\section{Table 1: Baseline clinical characteristics.}

\begin{tabular}{|lccc|}
\hline & Durable polymers & Biodegradable polymers & p value \\
\hline Number of patients (N) & 25 & 22 & 0.385 \\
\hline Age (years $\mathbf{S D}$ ) & $60.6( \pm 11.1)$ & $65.1( \pm 11.3)$ & 0.867 \\
\hline Gender (male \%) (N) & $88.0(22)$ & $86.4(19)$ & 0.626 \\
\hline Diabetes mellitus (\%) (N) & $48.0(12)$ & $40.9(9)$ & 0.918 \\
\hline Hypertension (\%) (N) & $76.0(19)$ & $77.3(17)$ & 0.753 \\
\hline Hyperlipidemia (\%) (N) & $68.0(17)$ & $63.6(14)$ & 0.191 \\
\hline Smoking (\%) (N) & $40.0(10)$ & $59.1(13)$ & 0.867 \\
\hline Hemodialysis patients (\%) (N) & $12.0(3)$ & $13.6(3)$ & 0.562 \\
\hline Peripheral Artery Disease (\%) (N) & $20.0(5)$ & $13.6(3)$ & 1.000 \\
\hline Cerebrovascular Disease (\%) (N) & $8.0(2)$ & $9.1(2)$ & 0.753 \\
\hline Hx of PCI (\%) (N) & $32.0(8)$ & $36.4(8)$ & 0.867 \\
\hline Hx of Myocardial Infarction (\%) (N) & $88.0(22)$ & $18.2(4)$ & 0.297 \\
\hline Hx of CABG (\%) (N) & $8.0(2)$ & $50.0( \pm 14.3)$ & 0.853 \\
\hline Left Ventricule Ejection Fraction, \% & $51.4( \pm 11.0)$ & $1.00(0.82-1.10)$ & 0.127 \\
\hline Serum Creatinine, mg/dL & & $100(22)$ & 0.052 \\
\hline (excluding hemodialysis patients) & $0.90(0.80-1.10)$ & $100(22)$ & 0.112 \\
\hline Prior medications & & $52.2(12)$ & 0.861 \\
\hline \multicolumn{1}{|c|}{ Statin (\%), N } & $80.0(20)$ & $95.4(21)$ & 1.000 \\
\hline Beta-blockers (\%), N & $84.0(21)$ & $95.4(21)$ & 1.000 \\
\hline ACEl/ARB (\%), N & $52.0(13)$ & & \\
\hline ASA (\%), N & $96.0(24)$ & $96.0(24)$ & \\
\hline Clopidogrel (\%), N & & & \\
\hline
\end{tabular}

Table 2: Angiographic data of the study patients.

\begin{tabular}{|c|c|c|c|}
\hline & Durable polymers & Biodegradable polymers & p value \\
\hline Mean stent length, mm & $30.0(24.0-61.0)$ & $56.0(33.0-65.0)$ & 0.015 \\
\hline Maximum stent diameter, mm & $3.00(2.75-3.00)$ & $3.00(2.68-3.00)$ & 0.818 \\
\hline Minimum stent diameter, $\mathbf{m m} \pm \mathbf{S D}$ & $2.74( \pm 0.24)$ & $2.65( \pm 0.29)$ & 0.451 \\
\hline Antegrade approach (\%), N & $100(25)$ & $95.4(21)$ & 0.274 \\
\hline Retrograde approach (\%), N & $0(0)$ & $4.5(1)$ & 0.460 \\
\hline Lesion length (>20 mm) (\%), N & $88.0(22)$ & $90.9(20)$ & 0.747 \\
\hline Multivessel disease (\%), N & $96.0(24)$ & $90.9(20)$ & 0.593 \\
\hline J-CTO Score, mean \pm SD & $2.9( \pm 0.4)$ & $3.0( \pm 0.4)$ & 0.537 \\
\hline Easy (\%), N & $0(0)$ & $0(0)$ & \\
\hline Intermediate (\%), N & $12.0(3)$ & $9.1(2)$ & \\
\hline Difficult (\%), $\mathrm{N}$ & $80.0(20)$ & $77.3(17)$ & \\
\hline Very difficult (\%), $\mathrm{N}$ & $8.0(2)$ & $13.6(3)$ & \\
\hline
\end{tabular}

Table 3: In-hospital follow-up and peri-interventional complications.

\begin{tabular}{|lccc|}
\hline & Durable polymers & Biodegradable polymers & p value \\
\hline In-hospital mortality (\%), N & $0(0)$ & $9.1(2)$ & 0.214 \\
\hline Emergent CABG (\%), N & $0(0)$ & $0(0)$ & NA \\
\hline Cardiac tamponade (\%), N & $0(0)$ & $0(0)$ & NA \\
\hline Coronary perforation (\%), N & $0(0)$ & $4.5(1)$ & 0.468 \\
\hline Stent thrombosis (\%), N & $0(0)$ & $4.5(1)$ & 0.468 \\
\hline Stroke (\%), N & $4.0(1)$ & $4.5(1)$ & 0 \\
\hline Hematoma (\%), N & $0(0)$ & $0(0)$ & NA \\
\hline Pseudoaneurysm (\%), N & $0(0)$ & $0(0)$ & NA \\
\hline
\end{tabular}

acute stent thrombosis, which was treated successfully by balloon angioplasty. Two patients had stroke during in-hospital follow-up, and they died because of their extensive cerebral infarct. We did not see any vascular access side complications such as blood transfusion need, hematoma, or pseudoaneurysm (Figure 1). 
Forty-five patients were discharged from the hospital in good health condition, and these patients were enrolled in the long- term follow-up evaluation (Table 4). Two patients died because of extensive stroke during in-hospital follow-up, and they were excluded

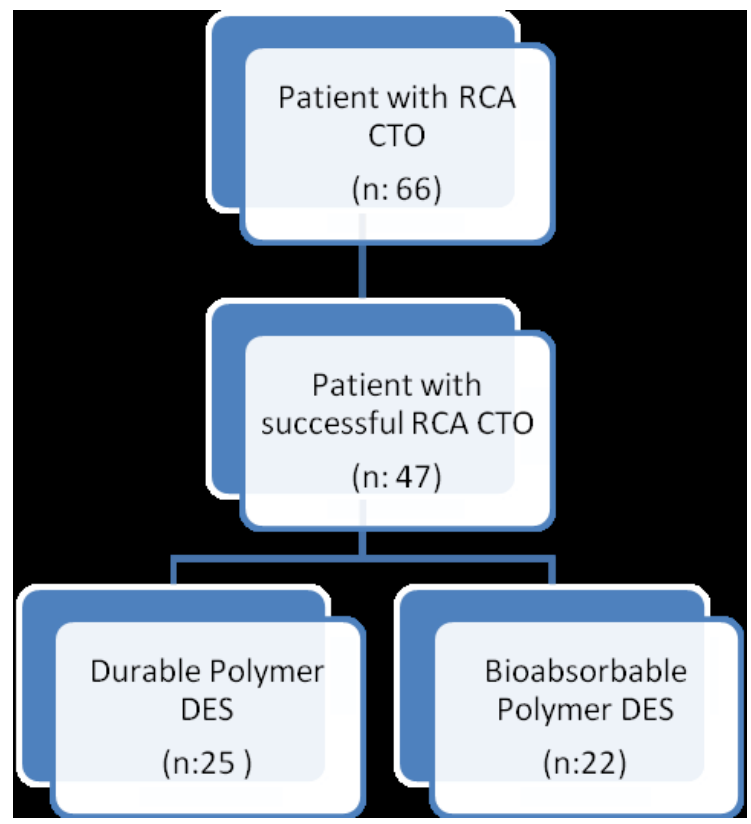

Figure 1: Study design. from long-term major adverse cardiac events (MACE) evaluation. The DP group had a longer followup period, but this was reaching strong statistical significance. This difference may be related with longer usage time of DP stents in our institution. We did not see any cardiac death or all-cause mortality in the longterm follow-up. Two patients had myocardial infarction from intervened vessels, and they were re vascularized successfully. We did not detect any difference between two polymer groups for target vessel revascularization (TVR) rates. TVR rates were $12.0 \%$ for the DP group and $9.1 \%$ for the BP group at the end of the 18 th month (hazard ratio $[\mathrm{HR}]=0.815 ; 95 \%$ confidence interval $[\mathrm{CI}]=0.123-5.418 ; \mathrm{p}=0.0 .832$ ). Composite MACE rates were $16.0 \%$ for the DP group and $15.0 \%$ for the BP group (hazard ratio $[H R]=0.926 ; 95 \%$ confidence interval $[\mathrm{CI}]=0.182-4.718 ; \mathrm{p}=0.927$ ) (Figure 2).

\section{Discussion}

This is an observational trial of RCA CTOs treated with BP-DES versus second-generation DP-DES and an18-month follow-up. In this study, we observed that BP-DES and second-generation DP-DES are similarly effective in the treatment of CTO lesions for RCA over 18 months follow-up. There were no differences between the two groups regarding the overall incidence

\begin{tabular}{|l}
\begin{tabular}{|lccc|}
\hline Table 4: Long-term follow-up results (at the end of $\mathbf{1 8}$ months). & & & \\
& Durable polymers & Biodegradable polymers & p value \\
\hline Cardiac death (\%), N & $0(0)$ & $0(0)$ & NA \\
\hline All cause mortality (\%), N & $0(0)$ & $0(0)$ & NA \\
\hline Myocardial infarction (\%), N & $4.0(1)$ & $4.5(1)$ & 1.000 \\
\hline Target vessel revascularization (TVR) (\%), N & $12.0(3)$ & $9.1(2)$ & 0.670 \\
\hline Major adverse cardiac events (MACE) (\%), N & $16.0(4)$ & $15.0(3)$ & 0.927 \\
\hline Median follow-up, months & $23.0(20.0-32.0)$ & $17.0(16.0-28.5)$ & 0.008 \\
\hline
\end{tabular}
\end{tabular}

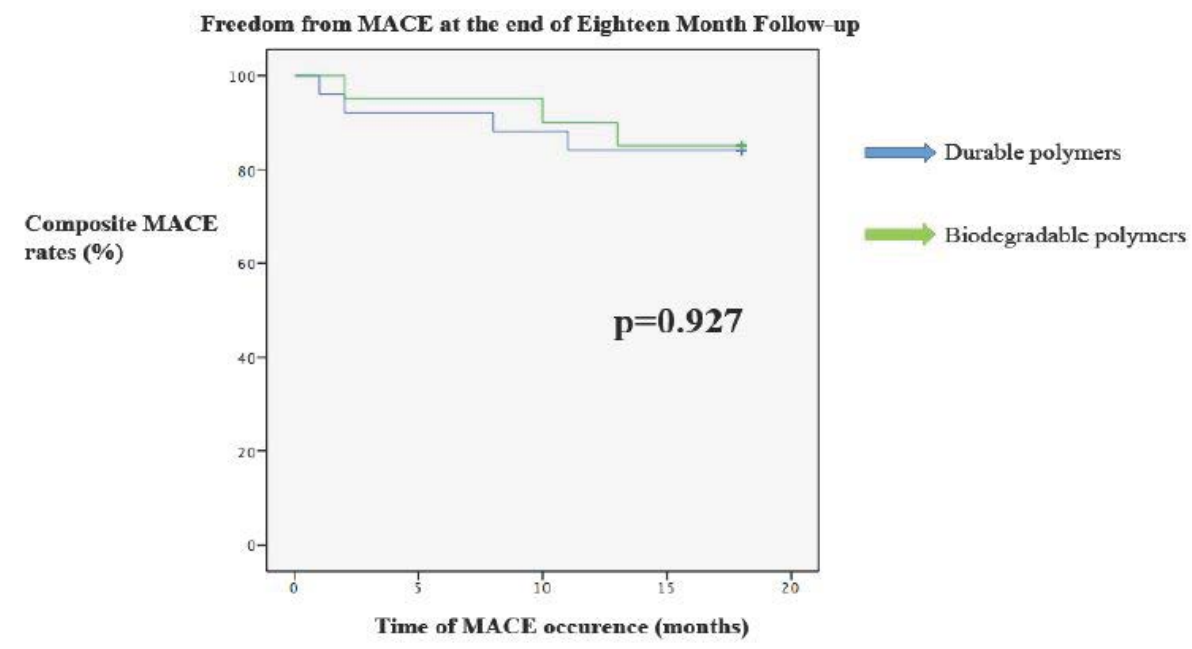

Figure 2: Composite MACE rates. 
of cardiac death or the overall incidence of MACE, despite the 18-month period of observation. The incidences of cardiac death and MACE in the two groups were still comparable after propensity score matching of all the patients.

BP-DES has been developed to overcome the limitations of DP-DES. Studies have shown that DPs coating first-generation DES are associated with chronic inflammation and delayed arterial healing, which might be responsible for the higher rates of very late stent thrombosis observed with first-generation DESs $[18,19]$.The BP-based DES and secondgeneration DP-DES have been shown to be safer and more effective than both BMS and first-generation DES [20-22]. However, few studies have compared BP-DES versus second-generation DP-DES [23]. Lupi et al. showed that BP-DES when compared with DP-DES significantly reduced TVR but without clear benefits on mortality, MI and LST rates [24]. Palmerini et al. published a big meta-analysis in 2014. In this trial, BP-DES were associated with superior clinical outcomes compared with BMS and first-generation DES and similar rates of cardiac death/MI, MI, and TVR compared with second-generation DP-DES but higher rates of definite ST than CoCr-EES [25]. Lupi et al. performed an updated meta-analysis comparing BP-DES and DP-DES. In comparison with DP-DES, BP-DES significantly reduced LST rates, without clear benefits on the other endpoints [26]. In these trials, the stents were used for non-CTO lesions. Lanka et al. compared first-generation DESs versus secondgeneration DESs in CTO lesions. Although all these first- and second-generation stents were DP stents, compared to first-generation DESs, second-generation DESs are associated with improved angiographic and clinical outcomes in CTO PCI and are the preferred stents for these challenging lesions [27]. In 2017, Markovic et al. published that Orsiro-SES resulted in a significant lower late lumen loss but with similar clinical results up to 24 months compared to the R-ZES after treatment of CTO lesions [28]. Teeuwen et al. investigate the efficacy and safety of the sirolimuseluting stent (SES) with BP compared with the everolimus-eluting stent (EES) with DP in successfully recanalized chronic total occlusions [29]. Overall, 330 patients were included the study. Clinically indicated target lesion and target vessel revascularization, target vessel failure, and definite or probable stent thrombosis were comparable between the SES and EES groups. In-stent late lumen loss was comparable between SES and EES. This randomized trial failed to show noninferiority of hybrid SES relative to EES in terms of in-segment late lumen loss in successfully recanalized CTOs. Furthermore, a statistically significant higher rate of binary restenosis was found with SES. Ghione et al. published that the use of a BES showed a reduction in MACE, TVR, TLR, and ST over time in the CTO subset with similar outcome as for nonCTO lesions, among 1,707 patients enrolled in the all-comers LEADERS trial; 81 with CTOs were treated with either a BES $(n=45)$ or an SES $(n=36)$. The primary endpoint was the occurrence of major adverse cardiac events (MACE): cardiac death, myocardial infarction (MI), and clinically indicated target vessel revascularization (TVR). Patients with CTO receiving a BES demonstrated a lower incidence of MACE $(22.2 \%$ vs. $38.9 \% ; \mathrm{p}=0.147$ ) with a significant reduction in TLR compared to patients receiving an SES with an incidence similar to that observed in the non-CTO group treated with BES. Definite ST at 5 years nearly halved in the BES group with no ST in the BES group after the first year [30].

\section{Study Limitations}

The number of the patients is the major limitation of our study. Longer follow-ups are needed to address long-term safety and efficacy. The advantage of BPbased DES over DP-based DES is expected to emerge in the late follow-up and, therefore, whether the observed differences would change with more extended followup is unknown.

\section{Conclusion}

This study shows that the efficacy of bio absorbable polymer DES is comparable to that of secondgeneration durable polymer DES treatment for right coronary artery CTO over 18 months follow-up. 
Executive summary

Objective: There are a few data regarding the long-term clinical outcomes of durable polymer (DP) drug-eluting stents (DES) versus bio absorbable polymer (BP) drug-eluting stents treatment in patients with right coronary artery (RCA) chronic total occlusion (CTO). The aim of this study was to compare the clinical outcomes of these stents according to their polymer-based difference.

Methods: Between June 2013 and August 2016, 66 RCA CTO patients enrolled in the study. Forty-seven patients with successful CTO recanalization of RCA via ante grade or retrograde approach using either DP $(n=25)$ and BP $(\mathrm{n}=22)$ were scheduled for 6,12 , and 18 months clinical follow-up. Primary clinical outcomes were cardiac death and major adverse cardiac events (MACE).

Results: RCA CTO success rate was $71 \%$. There was no difference in Japanese-CTO (JCTO) scores between two groups. Total stent length was longer in BP group, and it was statistically significant $(p=0.015)$. The incidence of cardiac death was not significant between the two groups. After propensity score matching, TVR rates were $12.0 \%$ for DP group and $9.1 \%$ for BP group at the end of the 18th month (hazard ratio $[H R]=0.815 ; 95 \%$ confidence interval $[C l]=0.123-5.418 ; \mathrm{p}=0.832$ ) and composite MACE rates were $16.0 \%$ for DP group and $15.0 \%$ for BP group (hazard ratio $[\mathrm{HR}]=0.926 ; 95 \%$ confidence interval $[\mathrm{Cl}]=0.182-4.718 ; \mathrm{p}=0.927)$.

Conclusion: This study shows that the efficacy of BP-DES is comparable to that second-generation DP-DES treatment for RCA CTO over 18-month follow-up.

\section{References}

1. Sianos G, Werner GS, Galassi AR, et al. Recanalisation of chronic total coronary occlusions: 82012 consensus document from the EuroCTO club. EuroIntervention. 8: 139-145 (2012).

2. Fefer P, Knudtson ML, Cheema AN, et al. Current perspectives on coronary chronic total occlusions: the Canadian Multicenter Chronic Total Occlusions Registry. J. Am. Coll. Cardiol. 59: 991-997 (2012).

3. Cho JR, Kim YJ, Ahn CM, et al. Quantification of regional calcium burden in chronic total occlusion by 64-slice multidetector computed tomography and procedural outcomes of percutaneous coronary intervention. Int. J. Cardiol. 145: 9-14 (2010).

4. Hsu JT, Kyo E, Chu CM, Tsuji T, Watanabe S. Impact of calcification length ratio on the intervention for chronic total occlusions. Int. J. Cardiol. 150: 135-141 (2011).

5. Patel VG, Brayton KM, Tamayo A, et al. Angiographic success and procedural complications in patients undergoing percutaneous coronary chronic total occlusion interventions: a weighted meta-analysis of 18,061 patients from 65 studies. J. Am. Coll. Cardiol. Intv. 6: 128-136 (2013).

6. Mehran R, Claessen BE, Godino C, et al. Long-term outcome of percutaneous coronary intervention for chronic total occlusions. JACC. Cardiovasc. Interv. 4: 952-961 (2011).

7. Stettler C, Allemann S, Wandel S, et al. Drug eluting and bare metal stents in people with and without diabetes: collaborative network meta-analysis. BMJ. 337: 1331-1336.

8. Niccoli G, Leo A, Giubilato $S$, et al. A meta-analysis of firstgeneration drug-eluting vs bare-metal stents for coronary chronic total occlusion: effect of length of follow-up on clinicaloutcome. Int. J. Cardiol. 150: 351-354 (2011).

9. Patel MR, Marso SP, Dai D, et al. Comparative effectiveness of drug-eluting versus bare-metal stents in elderly patients undergoing revascularization of chronic total coronary occlusions: results from the National Cardiovascular Data Registry, 2005-2008. JACC. Cardiovasc. Interv. 5: 1054-1061 (2012).
10. Rolf A, Werner GS, Schuhback A, et al. Preprocedural coronary CT angiography significantly improves success rates of PCI for chronic total occlusion. Int. J. Cardiovasc. Imaging. 29: 18191827 (2013).

11. Sianos G, Werner GS, Galassi AR, et al. Recanalization of chronic total coronary occlusions: 2012 consensus document from the EuroCTO club. EuroIntervention. 8: 139-145 (2012).

12. Fefer P, Knudtson ML, Cheema AN, et al. Current perspectives on coronary chronic totalocclusions: the Canadian Multicenter Chronic Total Occlusions Registry. J. Am. Coll. Cardiol. 59: 991-997 (2012).

13. Valenti R, Vergara R, Migliorini A, et al. Predictors of reocclusion after successful drug-eluting stent-supported percutaneous coronary intervention of chronic total occlusion. J. Am. Coll. Cardiol. 61(5): 545-550 (2013).

14. Godino C, Bassanelli G, Economou FI, et al. Predictors of cardiac death in patients with coronary chronic total occlusion not revascularized by PCI. Intern. J. Cardiol. 168(2): 1402-1409 (2013).

15. Sianos G, Werner GS, Galassi AR, et al. Recanalisation of chronic total coronary occlusions: 2012 consensus document from the EuroCTO club. EuroIntervention. 8(1): 139-145 (2012).

16. Cutlip DE, Windecker S, Mehran R, Academic Research Consortium. Academic Research Consortium. Clinical end points in coronary stent trials: a case for standardized definitions. Circulation. 115: 2344-2345 (2007).

17. Cutlip DE, Windecker S, Mehran R, et al. Clinical end points in coronary stent trials: a case for standardized definitions. Circulation. 115(17): 2344-2351 (2007).

18. Joner M, Finn AV, Farb A, et al. Pathology of drug-eluting stents in humans: delayed healing and late thrombotic risk. J. Am. Coll. Cardiol. 48: 193-202 (2006).

19. Virmani R, Guagliumi G, Farb A, et al. Localized hypersensitivity and late coronary thrombosis secondary to a sirolimus-eluting stent: should we be cautious? Circulation. 109: 701-705 (2004).

20. Stefanini GG, Byrne RA, Serruys PW, et al. Biodegradable polymer drug-eluting stents reduce the risk of stent thrombosis 
at 4 years in patients undergoing percutaneous coronary intervention: a pooled analysis of individual patient data from the ISAR-TEST 3, ISARTEST4, and LEADERS randomized trials. Eur. Heart. J. 33: 1214-1222 (2012).

21. Palmerini T, Biondi-Zoccai G, Della RD, et al. Stent thrombosis with drug-eluting and bare-metal stents: evidence from a comprehensive network meta-analysis. Lancet. 379:1393-1402 (2012).

22. Bangalore S, Kumar S, Fusaro M, et al. Short- and long-term outcomes with drug-eluting and bare-metal coronary stents: a mixed-treatment comparison analysis of 117762 patient-years of follow-up from randomized trials. Circulation. 125: 28732891 (2012)

23. Smits PC, Hofma S, Togni M, et al. Abluminal biodegradable polymer biolimus-eluting stent versus durable polymer everolimus-eluting stent (COMPARE II): a randomised, controlled, non-inferiority trial. Lancet. 381: 651-660 (2013).

24. Alessandro L, Andrea R, Gioel G, et al. Biodegradable versus durable polymer drug eluting stents in coronary artery disease: insights from a meta-analysis of 5,834 patients. Eur. J. Prev. Cardiol. 21(4): 411-424 (2014).

25. Tullio P, Giuseppe B, Diego DR, et al. Clinical Outcomes With Bio absorbable Polymer- Versus Durable Polymer-Based Drug-Eluting and Bare-Metal Stents Evidence From a Comprehensive Network Meta-Analysis. J. Am. Coll. Cardiol. 63(4): 299-307 (2014).
26. Lupi A, Gabrio SG, Rognoni A, et al. Meta-analysis of bio absorbable versus durable polymer drug-eluting stents in 20,005 patients with coronary artery disease: an update. Catheter. Cardiovasc. Interv. 83(6): E193-E206 (2014).

27. Lanka V, Patel VG, Saeed B, et al. Outcomes with first- versus second-generation drug-eluting stents in coronary chronic total occlusions (CTOs): a systematic review and meta-analysis. J. Invasive. Cardiol. 26(7): 304-310 (2014).

28. Markovic S, Lützner M, Dragomir S, Rottbauer W, Wöhrle J. Angiographic and clinical outcomes after recanalization of coronary chronic total occlusions with the Orsiro sirolimuseluting stent compared with the resolute zotarolimus-eluting stent. Coron. Artery. Dis. 28(5): 376-380 (2017).

29. Teeuwen K, vander SRJ, Adriaenssens T, et al. Randomized Multicenter Trial Investigating Angiographic Outcomes of Hybrid Sirolimus-Eluting Stents With Biodegradable Polymer Compared With Everolimus-Eluting Stents With Durable Polymer in Chronic Total Occlusions: The PRISON IV Trial. JACC. Cardiovasc. Interv. 10(2): 133-143 (2017).

30. Ghione M, Wykrzykowska JJ, Windecker S, et al. Five-year outcomes of chronic total occlusion treatment with a biolimus A9-eluting biodegradable polymer stent versus a sirolimuseluting permanent polymer stent in the LEADERS all-comers trial. Cardiol. J. 23(6): 626-636 (2016). 